\title{
Introducing the Medical Ethics Bowl
}

Allison Merrick, Rochelle Green, Thomas V. Cunningham, Leah R. Eisenberg, and D. Micah Hester

\section{Author biographies}

Allison Merrick, $\mathrm{PhD}$, is Assistant Professor of Philosophy in the Department of Philosophy and Interdisciplinary Studies at the University of Arkansas at Little Rock (UALR), Little Rock. She coaches the UALR Ethics Bowl team and is Treasurer of the Eastern Society for Women in Philosophy.

Rochelle Green, PhD, is Assistant Professor of Philosophy in the Department of Philosophy and Interdisciplinary Studies at the University of Arkansas at Little Rock (UALR), Little Rock. She coaches the UALR Ethics Bowl team and is Executive Secretary of the Eastern Society for Women in Philosophy.

Thomas V. Cunningham, PhD, MA, MS, is Assistant Professor of Medical Humanities and Internal Medicine at the University of Arkansas for Medical Sciences (UAMS), Little Rock, and Clinical Ethicist at UAMS and Arkansas Children's Hospital.

Leah R. Eisenberg, JD, MA, is Assistant Professor of Medical Humanities at the University of Arkansas for Medical Sciences (UAMS), Little Rock, and Clinical Ethicist at UAMS and Arkansas Children's Hospital.

D. Micah Hester, $\mathrm{PhD}$, is Professor of Medical Humanities and Pediatrics, and Chief of the Division of Medical Humanities at the University of Arkansas for Medical Sciences (UAMS), Little Rock. He is also is co-course director of the Practice of Medicine course in which ethics education occurs during the first two years of medical school at UAMS, and Clinical Ethicist at UAMS and Arkansas Children's Hospital.

CORRESPONDING AUTHOR:

D. Micah Hester, PhD

Division of Medical Humanities

UAMS College of Medicine

4301 W. Markham St., \#646

Little Rock, AR 72205

DMHester@uams.edu 


\section{Abstract \& Key Words}

Although ethics is an essential component of undergraduate medical education, research suggests current medical ethics curricula face considerable challenges in improving students' ethical reasoning. This paper discusses these challenges and introduces a promising new mode of graduate and professional ethics instruction for overcoming them. We begin by describing common ethics curricula, focusing in particular on established problems with current approaches. Next, we describe a novel method of ethics education and assessment for medical students that we have devised, the Medical Ethics Bowl. Finally, we suggest pedagogical advantages to MEBs when compared to other ethics curricula.

Key Words: ethics curriculum; medical ethics bowl; undergraduate medical education; ethical reasoning

\section{Introducing the Medical Ethics Bowl}

Ethics is an essential component of medical school curriculum. ${ }^{1}{ }^{3} 4$ However, many question the efficacy of ethics curriculum in undergraduate medical education. ${ }^{5}$ Indeed, findings from a number of distinct studies are, at best, troubling. ${ }^{6}$ Research indicates some medical students exhibit minimal development in moral maturity during their four years of undergraduate medical education. ${ }^{7}$ Yet, other studies suggest students make gains in ethical reasoning during their first two years of school and then undergo a "detrimental ethical shift" during their third and fourth years of medical education. 8910111213 Regardless of the ultimate reliability of such findings, they paint a bleak picture for undergraduate medical education in ethics, suggesting that current methods face considerable challenges in improving students' ethical reasoning.

The aim here is to discuss these challenges and to introduce a promising new mode of graduate and professional ethics instruction for overcoming them. We begin by describing common ethics curricula, as discussed in contemporary medical education literature, focusing in particular on established problems with current approaches. Next, we describe a novel method of ethics education and assessment for medical students that we have devised, the Medical Ethics Bowl (or MEB), distinguishing it from the Intercollegiate Ethics Bowl sponsored by the Association for Professional and Practical Ethics. ${ }^{14}$ Finally, we suggest pedagogical advantages to MEBs when compared to other ethics curricula. 


\section{Aims and Challenges of Medical School Ethics Education}

The rise of ethics education in healthcare and other professional education stems from an awareness of the need for greater ethical sensitivity and reasoning in professional practice. ${ }^{15} 16$ While ethics curricula must satisfy a number of objectives, at its base, all professional ethics education attempts to help students develop a greater awareness of ethical issues that arise for professionals as well as provide ways of dealing with them.

There are no standard methods or curricula for teaching ethics in medical schools. Educators employ lectures, videos, discussion, team-based learning and other modalities. Perhaps the most common approach is to use case studies to educate and evaluate moral sensitivity and reasoning. ${ }^{17}$ For that reason, the small group discussion model focusing on cases, has been championed as the most effective way to deliver ethics education to medical students. ${ }^{18}$ This pedagogical strategy delivers content through lectures and readings, which then becomes the foundation for discussing primary themes during case analyses in small group settings. Advantages of this approach include the ability to fit the format into existing medical school curricula, and allow medical students to discuss and work through complex, realistic, ethical cases similar to those that they will confront as physicians. A number of studies support the success of this pedagogy. ${ }^{192021}$ By the end of the preclinical years, medical students who participate in this type of training demonstrate the ability to identify the central ethical issues in a case and offer ways of adjudicating the issue. ${ }^{22}$

However, although small group, case-based ethics curricula are effective in teaching ethics to medical students early in their training, some studies suggest that gains in moral sensitivity in the preclinical years are rarely long-lasting. Studies of moral sensitivity and moral reasoning suggest basic challenges for undergraduate medical student education in ethics. ${ }^{23}$ Principally, they indicate that regardless of their baseline morality prior to beginning medical school, medical students experience a decline in their moral senses during - and perhaps as a consequence of - undergraduate medical education. This is consistent with other findings of similar reductions in medical student empathy during the same time frame ${ }^{24}$ and the marginalization of medical ethics content in the "hidden curriculum" of undergraduate medical education - the informal education students absorb through the culture of medical practice as opposed to the formal education they receive in medical knowledge and theory. ${ }^{25}$

As educators, we have observed additional challenges medical students face in their ethics education, which echo others' experiences. ${ }^{26}$ First, because of the prodigious amount of information medical students are presented during their first two years of training, they typically adopt a strategy of selectively reading assignments, attending large lectures, and participating in small group discussions. In this context, ethics appears to be deprioritized because, from the students' perspective, it is both more demanding and less rewarding than other subjects. Unlike other subjects, ethics requires students to reflect on their personal moral sensibilities in addition to understanding theory and becoming familiar with key topics and cases. Yet, also unlike other courses, poor marks in ethics rarely cause academic failure given the way performance in 
medical school curriculum is typically evaluated. Thus, ethics is both more demanding because of the burdens of self-reflection and it is less rewarding because excellence in ethics does not contribute significantly to grades or test scores.

Secondly, medical students face challenges in how they individually conceptualize the value of ethics in the medical context. While many indicate morality is important to them, they also suggest it is a subject matter that relates to their personal, as opposed to professional, actions. Instead, students often conflate the domains of institutional policy and health law (especially risk management and malpractice litigation) with medical ethics. While these domains are obviously also of essential concern for future physicians, they remain distinguishable from ethical issues likely to emerge in practice. Consequently, rigorous and effective ethics education within the medical school context faces the challenge of distinguishing ethics from other aspects of professionalism.. The task is to create avenues for students to explore and internalize the value of ethics in their education, and further, to conceptualize this education as providing a worthwhile set of skills and practices relevant for their future medical careers. Furthermore, this task is compounded by the intensity of medical student education and the competing demands for students' attention, even when students recognize the value of ethics education, as many studies and self reports indicate they do. 27282930

The question that we must confront is "How to design medical ethics curriculum such that it meets these challenges?" Our response has been to develop the Medical Ethics Bowl. In order to appreciate fully the ways in which this new alternative helps to overcome such challenges, it is useful to distinguish it from the related Intercollegiate Ethics Bowl (ICEB) method that inspired our development of the MEB.

\section{Intercollegiate vs. Medical Ethics Bowls}

The ICEB was introduced by Robert Landenson of the Illinois Institute of Technology as a way of encouraging college students to engage in serious moral discourse. In his description, "The Ethics Bowl is an activity that combines a valuable and distinctive educational experience for students with the excitement and fun of a competitive team game." 3132 The format and content are designed to apply to any number of contexts in which education in ethical sensitivity and reasoning is a goal.

ICEB is an annual, regional and national competition of intercollegiate teams administered through the Association for Practical and Professional Ethics (APPE). Colleges around the country develop extracurricular teams of undergraduate students, and the APPE furnishes a series of cases for competition that cover a wide variety of ethical issues - e.g., voting rights, death penalty, gun control, Facebook invasion of privacy, sustainable growth and development, hiring practices, medical ethics, grade inflation, and plagiarism. Each team spends hours in preparation and practice prior to the competition, working through eight specific cases.

During an ICEB competition, a moderator begins each match by posing a question to the four-student team presenting first based on one of the cases, chosen by the organizers on the day 
of the event, The two teams from different schools attempt to lay bare the central ethical issues, present a reasoned argument for their team's position, and offer reasons why someone might oppose their viewpoint. ICEB presentations are judged by an independent panel of judges, composed of community members interested in ethics and moral reasoning, such as college professors, high school teachers, and local professionals. Teams are judged in terms of the clarity and intelligibility of the presentation in addition to the relevance of the argument and supporting evidence offered.

Important educational features of the ICEB are the focus on developing sound argument, working as a team, pursuing careful research and reflection and acquiring skill in argument presentation. According to Landenson, the ICEB can serve the following educational aims: "(a) the development of ethical understanding in connection with complex, ambiguous, and difficult to resolve issues; and (b) the fostering of key virtues associated with democratic deliberation."33

Following the general form of its ICEB cousin, the MEB is designed as both a formative and evaluative modality for teaching aspects of ethics to medical students. It differs importantly from ICEB in its aims. While the ICEB is an educational forum, the "fun" of ICEB is in the competitive character, where regional and national champions are crowned. The MEB, on the other hand, while retaining a pseudo-competitive form, is primarily a curricular event, designed not to identify a champion but to stimulate learning and evaluate the extent of that learning.

Given that MEBs are curricular, rather than extracurricular, modifications to the form and content of ICEB had to be made as we designed the MEB. For instance, because the medical student body is large (approximately 170 medical students in each class at the University of Arkansas Medical School), students are divided into teams of about 6 which remain constant throughout the academic year. Similar to ICEB, teams of students participate in presenting and responding to arguments with each other on topics raised through the use of pre-assigned cases. However, unlike ICEB, two cases are initially presented to all the students during a 1-hour class session, held 1-2 weeks before the MEB matches. During this preparatory period, students are encouraged to ask questions about the case or the MEB process, and time is allotted for them to join with their teams and start planning their approaches to the cases. Thereafter, they are expected to perform any necessary research to generate a cogent and thorough response to the ethically challenging cases and are scored in part based on how well they accomplish that task.

Each MEB match consists of two teams of 6-7 students and two judges. An MEB match is timed at 60 minutes and consists of two 27-minute rounds. Each match is spaced 1 hour and 15 minutes apart to allow time for introductions, judges' scoring, and optional discussion with teams after the match concludes.

The team presenting first is determined by a coin flip. The round begins when the team presents its 8-minute position on the assigned case (which includes ethical analysis, proposed ethical resolution, and substantive arguments for and against their own proposal). Next, the opposing team presents a 6-minute response; followed by the presenting team's 5-minute rebuttal. After formal presentations and responses are finished, a panel of judges questions the presenting team and listens to their 8-minute response. Judges ask questions with the intention of helping 
students to think more deeply about a specific issue, to consider implications of their arguments they had not previously identified, or to examine more carefully a dimension of the ethical theme under consideration. After the round, the two teams switch roles, with the presenting team now being the responding team and the responding team taking the presenting role in the second case. Once the pattern repeats, the match concludes.

The judges then have six minutes in which to discuss the event with the students and roughly 15 minutes to confer, write down their scores using a specific scoring sheet (available via email to the corresponding author), and take a break before the next match.

The MEB curriculum is faculty-intensive because there are a minimum of 28 teams that participate in matches (which means every MEB involves fourteen matches). Judges are recruited from faculty with expertise in ethics and/or medicine.. To prepare faculty for judging, two of us with ICEB experience (AM and RG), designed a 3-hour training session. The session was repeated several times and video-recorded for absent faculty, so all faculty volunteers for MEB judging received training prior to judging. Faculty judges are paired so that each match has a judge whose expertise is in medicine and a judge whose expertise is in ethics, humanities, or social science.

On ethics bowl days, students are assigned a 1 hour and 15 minute time slot and a room for their matches. Judges are also given rooms and times, enabling up to 5 ethics bowl sessions to be underway simultaneously, allowing each MEB at UAMS to accommodate 170 students in a 40 hour time block. Ten faculty volunteers judge 3 matches each during the afternoon

The basic aim of the MEB curriculum is to help students learn how to produce and present an argument for an ethical position in response to a realistic clinical situation. As part of the MEB curriculum, students are given GRACE, an acronym for a mnemonic pedagogical tool, developed by one of us (DMH). GRACE, provides a conceptual structure for better identifying, appreciating, and understanding ethical issues that are often raised in medical cases.

G: Get the whole story. Ask: What are the technical, personal, and social facts, values, and beliefs pertinent to the situation?

R: Recognize obligations. Ask: What is expected of the professionals, patients, families, and others in the case as moral agents?

A: Accept responsibilities / Avoid over-reaching. Ask: What is the scope of those roles in the situation? What falls outside those roles?

C: Consider consequences. Ask: What are the possible outcomes of proposed actions under the circumstances.

E: Evaluate character. Ask: How might the proposed actions be viewed by others within the community, institution, or profession?

This structure also provides a basis by which judges can score the case presentations. A strong presentation should include academically acceptable researched materials that relate to cogent responses to the GRACE considerations. The best presentations will be well researched and answer a majority of the questions captured by GRACE. Accordingly, each case will require 
that students meet together outside of class time and seek out the appropriate resources necessary to fully develop the complexities present in each of the cases.

\section{Pedagogical Benefits of the MEB}

When compared to traditional undergraduate medical ethics curriculum, our experiences has been that the MEB curriculum offers a number of pedagogical benefits, making it a promising method for overcoming challenges to undergraduate medical education in ethics. As a gauge to measure these benefits, we can consider the five objectives for medical ethics education enumerated by R. Eckles:

1. To enable physicians to examine and affirm their own personal and professional commitments.

2. To teach physicians to recognize the humanistic and ethical aspects of medical careers.

3. To equip physicians with a foundation of philosophical, social, and legal knowledge.

4. To enable physicians to employ this knowledge in clinical reasoning.

5. To equip physicians with the interactional skills needed to apply this insight, knowledge, and reasoning to human clinical care. ${ }^{34}$

Given these five objectives, we believe that the MEB can help students reach those goals in the following ways:

1. As part of building a cogent case for MEB, students are asked to identify ethical quandaries and the role played by conflicting values. Part of a successful MEB presentation involves students recognizing the values of the stake-holders described in the case, as well as reflect on their their own values and how values affect decision making.

2. During the MEB students are asked to produce and present an argument for an ethical position in response to a realistic clinical situation that inevitably involves the fears and vulnerabilities of patients and their families. As such, students can grow in recognizing the humanistic and ethical aspects essential in a medical career.

3. A cogent MEB presentation requires students to consider the medical, ethical, legal, and psychological facts, along with the philosophical underpinnings and relevant values and beliefs pertinent to the case, thus providing a foundation in these areas as well as developing awareness and understanding of the overlapping complexities of the issues involved.

4. MEB is a team-based process, requiring students to work together to develop good arguments. Insofar as the MEB cases represent realistic clinical situations, students can practice their ethical reasoning skills as a team-based effort, and experience the importance of this approach to problem solving in a clinical setting.

5. The final goal is to equip physicians with the communication and interactional skills needed to apply their moral reasoning skills, insights, and clinical knowledge to clinical 
care. Students must not only formulate logical arguments for their positions and effectively communicate their findings with the opposing team; they are also asked to interpret charitably and respond professionally to the findings of the opposing teamagain practicing and developing competencies in interpersonal communication.

In addition to these five skills, MEB has the potential to develop both extrinsic and intrinsic motivation. Current research in education indicates the importance of distinguishing between these two types of motivation. At its most basic, extrinsic motivation involves "doing something because it leads to a separable outcome." ${ }^{, 35}$ When learning, a person is extrinsically motivated by factors like grades or the idea of rewards once a particular task or skill is completed and mastered. The MEB is likely to develop motivation of this order because of the competitive format. That is, students may find themselves motivated to construct the best case possible in order to score well in a match. If this is indeed the case, then a mode of extrinsic motivation is developed.

By contrast, intrinsic motivation, or "doing something because it is inherently interesting or enjoyable," has been shown to be affected by positive feedback when a learning activity occurs. ${ }^{36}$ The key difference in this situation is that a person who is intrinsically motivated performs an action, not for some external reward, but because the action is seen as valuable initself. By contrast with other modes of instruction that offer delayed feedback (e.g. such as requiring students to submit essays and returning those essays at the next course meeting), medical ethics bowls - through both the questions posed by judges and the scores given during the match — provide students with immediate affirmative feedback. As a result the MEB may prove to be a valuable pedagogical tool in generating intrinsic motivation because it provides a means of translating qualitative assessments of argument, reasoning, and engagement with alternative viewpoints into quantitative measures using the judges rubric and score sheet.

Finally, participating in MEBs may help students develop moral sensitivity and improve moral reasoning. In the educational context, "moral sensitivity" may be well and simply defined as the ability to recognize ethical dilemmas, ${ }^{37}$ while "moral reasoning" is demonstrated by a student's ability to respond cogently to a recognized ethical issue. ${ }^{38}$ Both moral sensitivity and moral reasoning may be assessed using case studies and vignettes. ${ }^{39} 404142$ For example, in a Toronto study medical students were asked to list all of the ethical issues present in expertprepared vignettes, with points awarded for recognizing issues in three domains: autonomy, beneficence and justice. ${ }^{434}$ Moral sensitivity was measured in terms of recognition of issues in the three domains, which increased from first-year students to second year students, decreased from second-year students to third-year students, and decreased from third-year to fourth-year students. Others have explored the effect of ethics education on medical students' moral reasoning by employing Kohlberg's theory of three levels of moral development, so-called preconventional morality, conventional morality, and postconventional morality. ${ }^{45}$ In one study, students at the University of Sherbrooke in Quebec, Canada completed a Moral Judgment Interview upon entry in their first year and again in their third year. Using this measure, students' moral reasoning declined significantly after three years of medical education. ${ }^{46}$ Participation in 
MEBs has the possibility to improve students' moral sensitivity and moral reasoning as measured in studies such as these.

\section{Conclusion}

Though ours may be the first medical school to adopt the MEB format as a required curricular modality, both engineering and business schools have adopted similar modalities and have reported success. ${ }^{47} 48$ Yet, the only empirical study of this pedagogical strategy remains inconclusive. ${ }^{49}$ With the launch of this new MEB curriculum in our medical school, we have a unique opportunity to study the effects of this mode of ethics instruction, which we plan to accomplish in the future by performing mixed methods research.

Presently, we have heard student feedback about the curriculum in two forms: individual discussions and class officer feedback to course directors. Individual discussions with students indicate that these students enjoy the MEB process - developing case presentations and interacting during the matches themselves. There is an energy in the room during matches that students can feel and seem to enjoy. However, class officers indicate that while the students like the format, they are concerned about the variability of judges scoring (a.k.a., inter-rater reliability or IRR). Of course, with multiple judges making subjective determinations (even when based on a common rubric), IRR is a challenge.

To address issues of IRR, student team are being assigned different judges across the two year curriculum, so that they are unlikely to be evaluated by the same judge multiple times. Thus, in the event that one or more judge deviates significantly (positively or negatively) in his or her evaluation of MEB matches, the teams will not be exposed to that bias more than once.

But even more concerning is that the students concerns may have the consequence of creating student apathy to the process because they believe that their efforts could go unrecognized and unrewarded depending on the judges they are assigned. We are addressing those concerns by changing our judges' evaluation materials to include more robust comments section. We hope that with increased comments, students will better understand how individual judges assessed the strengths and weaknesses of their presentations.

As we learn more about the strengths and weaknesses of medical ethics bowls, we aim to codify our findings and disseminate them widely. We hope that the insights we developed will be of use to those involved in developing medical ethics curriculum now and in the future.

\footnotetext{
${ }^{1}$ Branch W. Supporting the moral development of medical ethics students. Journal of General Internal Medicine 2000;15(7):503-508.

${ }^{2}$ Bryan CS, Babelay, AM. Building character: A model for reflective practice. Academic Medicine, 2009;84(9):1283-1288.

${ }^{3}$ Doukas D, McCullough L, Wear S. Project to rebalance and integrate medical education (PRIME) investigators. Perspective: medical education in medical ethics and humanities as the foundation for developing medical professionalism. Academic Medicine 2012;87(3):344-341.

${ }^{4}$ Millstone M. Teaching medical ethics to meet the realities of a changing health care system. Bioethical Inquiry 2014;11:213-221.
} 
${ }^{5}$ E.g., Eckles R, Meslin E, Gaffney M, Heft, P. Medical ethics education: Where are we? Where should we be going? A review. Academic Medicine 2005;80:1143-1154.

${ }^{6}$ Lehmann L, Kasoff W, Koch P, Federman D. A survey of medical ethics education at US and Canadian medical schools. Academic Medicine 2004;79(7): 682-689.

${ }^{7}$ See note 1.

${ }^{8}$ Goldie J. The detrimental ethical shift towards cynicism: Can medical educators help prevent it?" Medical Education 2004;38:232-238.

${ }^{9}$ Baykara ZG, Demir SG, Yaman S. The effect of ethics training on students recognizing ethical violations and developing moral sensitivity. Nursing Ethics 2014: 0969733014542673.

${ }^{10}$ See note 1 .

${ }^{11}$ Hébert PC, Messlin EM, Dunn EV. Measuring the ethical sensitivity of medical students: a study at the university of Toronto. Journal of Medical Ethics 1992;18:142-147.

${ }^{12}$ Patenaude J, Niyonsenga T, Farard D. Changes in students' moral development during medical school: a cohort study. Canadian Medical Association Journal 2003;168(7):840-844.

${ }^{13}$ Self D, Wolinsky F, Baldwin, D. The effect of teaching medical ethics on medical students' moral reasoning. Academic Medicine 1989;64:755-759.

${ }^{14}$ Landenson RF. The educational significance of the ethics bowl. Teaching Ethics 2001;1:63-78.

${ }^{15}$ Rothman, DJ. Strangers at the bedside: A history of how law and bioethics transformed medical decision-making. Basic Books 1991.

${ }^{16}$ See note 1.

${ }^{17}$ E.g., Frasser C, McGuire AL, Erdman K, Nadalo D, Scott S, Waters V. The ethics workup: A case-based approach to ethical decision-making instruction. Journal of Physician Assistant Education 2007;18(1):34-41.

${ }^{18}$ Goldie J. Review of ethics curricula in undergraduate medical education. Medical Education 2000;34:108-119.

${ }^{19}$ Goldie J, Schwartz L, McConnachie A, Morrison J. The impact of modern medical curriculum on students' proposed behaviour on meeting ethical dilemmas. Medical Education 2002;38:942-949.

${ }^{20}$ Goldie J, Schwartz L, McConnachie A, Morrison J. Students' attitudes and potential behaviour with regard to whistle blowing as they pass through a modern medical curriculum. Medical Education 2003;37:368-375.

${ }^{21}$ See note 8 .

${ }^{22}$ See note 19 .

${ }^{23}$ See note 1.

${ }^{24}$ Newton BW, Barber L, Clardy J, Cleveland E, O’Sullivan P. Is there hardening of the heart during medical school? Academic Medicine 2008;83(3):244-249.

${ }^{25}$ Hafferty FW, Franks R. The hidden curriculum, ethics teaching, and the structure of medical education. Academic Medicine 1994;69(11):861-871.

${ }^{26}$ Perkins H, Geppert C, Hazuda H. Challenges in teaching ethics in medical schools. American Journal of the Medical Sciences 2000;319(5):273-278.

${ }^{27}$ Christakis DA, Feudtner C. Ethics in a Short white coat: The ethical dilemmas that medical students confront. Academic Medicine 1993;68(4):249-54.

${ }^{28}$ Terndrup C. A student's perspective on medical ethics education. Journal of Religion and Health 2013;52:1073-1078.

${ }^{29}$ Cordingley L, Hyde C, Peters S, Vernon B, Bundy C. Undergraduate medical students' exposure to clinical ethics: a challenge to the development of professional behaviours?. Medical Education 2007;41(12):1202-1209.

${ }^{30}$ Howard F, McKneally MF, Upshur RE, Levin AV. The formal and informal surgical ethics curriculum: views of resident and staff surgeons in Toronto. The American Journal of Surgery 2012;203(2):258-265.

${ }^{31}$ See note 14.

${ }^{32}$ Cf. Borrego AM. Ethics bowls exercise students' moral muscles. Chronicle of Higher Education, 2004;March 5:50,A31.

${ }^{33}$ See note 14, pp. 76.

${ }^{34}$ See note 5, pp. $1145-46$

${ }^{35}$ Ryan R, Deci E. Intrinsic and extrinsic motivations: classic definitions and new directions. Contemporary Educational Psychology 2000;25:54-67.

${ }^{36}$ See note 35 .

${ }^{37}$ See note 1, pp. 505.

${ }^{38}$ Savulescu J, Crisp R, Fulford KWM, Hope T. Evaluating ethics competence in medical education. Journal of Medical Ethics 1999;25:367-374. 
${ }^{39}$ See note 11 .

${ }^{40}$ See note 20 .

${ }^{41}$ See note 17.

${ }^{42}$ Akabayashi A, Slingsby BT, Kai I, Nishimura T, Yamagishi A. The development of a brief and objective method for evaluating moral sensitivity and reasoning in medical students. BMC Medical Ethics 20045(1):1.

${ }^{43}$ See note 11 .

${ }^{44} \mathrm{cf}$. note 1.

${ }^{45}$ Kohlberg L. The psychology of moral development: Moral stages, their nature and validity. vol two of essays in moral development San Francisco: Harper \& Row 1984.

${ }^{46}$ See note 12, pp. 843.

${ }^{47}$ Cruz JA, Frey WJ. An effective strategy for integrating ethics across the curriculum in engineering: an abet 200 challenge. Science and Engineering Ethics 2003;9:543-568.

${ }^{48}$ Collins D. Creating environmental change through business ethics and society course. In Advancing Bioethics Education ed. Swanton, Fisher. Charlotte: Information Age Publishing 2008:241-263.

${ }^{49}$ See note 48 . 